\title{
E-commerce Trends and Opportunities in BRICS countries
}

\author{
Svetlana Gusarova ${ }^{1, *}$, Igor Gusarov ${ }^{1}$, and Margarita Smeretchinskiy ${ }^{2}$ \\ ${ }^{1}$ Plekhanov Russian University of Economics, 117997 Moscow, Russia \\ ${ }^{2}$ York University, Schulich School of Business, 4700 Toronto, Canada
}

\begin{abstract}
Introduction of information technologies, transfer to the digital economy and the development e-commerce are on the agenda all over the world today. BRICS countries (Brazil, Russia, China, South Africa) pay great attention to the development of e-commerce and plan to strengthen intra-group cooperation in this area. An increase of the e-commerce is a new paradigm of the development of international trade of the «five» countries. It can become their economic growth driver, especially during the crisis due to the coronavirus pandemic. This problem is important, but still insufficiently studied and not enough reflected in the economic researches. Authors revealed the advantages, problems and the main directions of the development of e-commerce in BRICS countries.
\end{abstract}

\section{Introduction}

The globalization of the digital economy is fundamentally changing the relationship between countries. In future, e-commerce may become one of the most important areas of their mutually beneficial cooperation, contributing to the further growth of their economies.

E-commerce includes electronic trading, electronic payment systems, Internet banking, Internet trading, Internet insurance, legal services, medical services, etc. Robust economic activity on the Internet or by using its capabilities led to the emergence of a new concept electronic commerce [1].

There are many definition of e-commerce. For example, World Trade Organization pointed out that the term electronic commerce is understood to mean the production, distribution, marketing, sale or delivery of goods and services by electronic means [2]. As to $\mathrm{OECD}$, e-commerce refers generally to all forms of transactions relating to commercial activities, including both organizations and individuals, that are based upon the processing and transmission of digital data, including text, sound, and visual images [3]. European Information Technology Observatory defines, that e-commerce is the carrying out of business activities that lead to an exchange of value across telecommunication network [4].

"BRICS E-commerce Cooperation Initiative" pointed out that e-commerce is playing an increasingly important role in promoting the growth of trade, industry transformation and job creation (BRICS E-commerce Cooperation Initiative) [5]. According to researchers from China, "the term "e-commerce" refers to any commercial transaction type that requires the transmission of information over the Internet. By definition, it uses the Internet as a

\footnotetext{
* Corresponding author: s-gusarova@mail.ru
} 
platform for communication and financial transactions or, at the same time, covering various business activities" [6]. A researcher from France emphasizes, that "the foreseeable future of e-business and e-commerce will be shaped by the sophistication of digital technology: advanced algorithmic and artificial intelligence, big data analysis, and the Internet of things" [7].

Governments all over the world are paying great attention to promote computer literacy to enable every citizen to participate in the global digital society. United Nations Educational, Scientific and Cultural Organization defined digital literacy as the ability to access, manage, understand, integrate, communicate, evaluate, and create information safely and appropriately through digital technologies for employment, decent jobs, and entrepreneurship. It includes competences that are variously referred to as computer literacy, ICT literacy, information literacy, and media literacy [8]. The involvement of citizens in digital society leads to the growth of social and material wellbeing, including through the availability of e-commerce.

Authors of the manuscript define the Intra-BRICS e-commerce cooperation as their further interaction in the field of trade on the base of: active use of electronic payment systems; introduction of the blockchain system as an alternative to international money transfer systems; use of BRICS currencies in mutual settlements and online lending; development and implementation of the common cryptocurrency (for example, BRICScoin) for mutual settlements (instead of the US dollar); growth of cross-border e-commerce, number of online stores, e-shoppers, Internet penetration, Share of e-commerce in GDP; expanding the range of e-commerce products on the use of the BRICS economies complementarity.

BRICS countries introduces mainly the following business models: B2B (Business-toBusiness); B2C (Business-to-Consumer); C2C (Consumer-to-Consumer); B2G (Businessto-Government).

E-commerce has increased significantly resulting in dramatic growth and acceptance worldwide. The volume of e-commerce worldwide is increasing annually and in 2017 reached US\$ 1.84 trillion (2017 Global Ecommerce Report) [9]. E-commerce growth can be ensured by the increase in the number of Internet users. According to Internet World Stats, there are $54.4 \%$ Internet users of the total world population in 2017 . About $49 \%$ of the world's Internet users live in Asia, 17\% - in Europe, 11\% - in Africa, 10.5\% - in Latin America and the Caribbean. The leadership of the Asian region is due to the demographic situation in the world. In 2018, 2.62 billion Internet users successing social network sites via electronic devices, that was 1.6 times more than in 2013 (Ecommerce Foundation, 2018) [10].

According to the experts of Global Rus Trade, the volume of e-commerce of BRICS countries is expected to increase 3 times within five years (Global Rus Trade) [11]. In 2017, the ministers of the «five» countries adopted the «BRICS E-commerce Cooperation Initiative» of the BRICS countries. To implement e-commerce expansion plan, it is necessary to study the development of e-commerce in BRICS countries.

\section{Materials and Methods}

The methodological and theoretical basis of the study is the methods of comparative and situational analysis and synthesis, methods of econometrics, graphical methods, a systematic approach based on the study of a set of factors that determine the role of ecommerce in the development of countries' economies, a quantitative method in assessing the phenomena under study, a method of grouping and generalization, expert assessment method. 
The theoretical basis of the research is the fundamental works of scientists and researchers in the field of electronic commerce development in the BRICS countries.

The empirical basis of the study, which ensures the reliability of conclusions, recommendations and proposals, is the scientific research papers of scientists, regulations of Brazil, Russia, India, China and South Africa, official statistics data, World Bank data, analytical reports of the World Economic Forum, the International Monetary Fund, World Trade Organization, OECD, UNESCO, BRICS E-commerce Cooperation Initiative, Association of Internet Commerce Companies, Ecommerce Foundation, Global Ecommerce Report, data from BRICS e-commerce companies. The authors also used materials from periodicals, data from sites on the Internet.

\section{Results and Discussion. E-commerce in BRICS countries}

E-commerce can become a driver of economic growth in the BRICS countries, especially during the crisis due to the coronavirus pandemic.

In 2017, Internet penetration in Brazil was $68 \%$ Internet users of the total population in Brazil [10]. Average share of Brazilian population using different media platforms is 58\% of Internet users. The share of e-shoppers was 38\% (using smartphones and tablets). In Brazil, the share of e-commerce in GDP was only $0.92 \%$. An increase of the e-commerce share in GDP can become an economic growth driver. The leading Brazilian e-commerce company operating on the B2C business model is B2W Digital with sales of R \$ 10.3 billion [12]. In 2016, Brazilian e-shoppers spent US\$ 2.4 billion in cross-border websites. Brazilian B2C turnover is the best among the countries of South America.

The leader among e-shops in Russia is the Chinese Aliexpress. China considers trade with Russia as an important project for entering the European market in accordance with the implementation of the One Belt - One Road Initiative. About $90 \%$ of online purchases of overseas Russian Internet users accounted for the supply of products from China.

The company Global Rus Trade is the leading Russian cross-border e-commerce platform operating on the basis of the B2B business model. The aim of Global Rus Trade is to promote an increase in the turnover of 16.5 thousand exporters of products and support for small and medium enterprises in achieving high export potential. Only $0.28 \%$ of Russian small and medium enterprises, according to the Ministry of Economic Development of Russia, are currently exporters of products, but at the same time they provide $6 \%$ of its export volume.

In 2017, the volume of the e-commerce market in Russia increased to 1.04 trillion rubles, the volume of cross-border transactions amounted to 374.3 billion rubles [13], most of which came to Russian customers from China. In 2018, share of cross-border ecommerce in Russia was only 14\%. The share of e-shoppers was $48 \%$ (using smartphones and tablets). Average spending per e-shopper in Russia rose from US\$ 589 in 2015 to US\$ 741 in 2018 [10].

In 2017, Internet penetration was $73 \%$ of Internet users of the total population in Russia. Social media penetration was $47 \%$ of Internet users. The share of e-shoppers was $48 \%$ (using smartphones and tablets). Contribution of e-commerce to GDP in Russia was 2.5\%, it can become an economic growth driver of the country. Russian online consumers still prefer cash on delivery, which in most other markets is very unusual today.

The expansion of e-commerce has recently received much attention in India. In 2018, retail e-commerce sales in India reached US\$ 32.7 billion, 1.3 times more than in 2017 and more than 3 times since 2015. But it is only $2.9 \%$ of total sales in 2018 [14]. And if compered with developed markets in the region, it is low figures. Over the past few years, more than US\$ 4 billion has been allocated to the development of e-commerce in India, including US\$ 1 billion invested by the Chinese company Alibaba. In 2022, Indian e- 
commerce market will grow to US\$ 71.94 billion [15], being the third in Asia-Pacific region, trailing only to China and Indonesia. Contribution to country's GDP is a key characteristic of the e-commerce development. In India it was only $0.9 \%$ - the smallest among BRICS countries [10]. An increase of the e-commerce share in GDP can become an economic growth driver of the country.

There is $40 \%$ Internet penetration (Internet users of the total population in India) in 2017 - less than the world average and the smallest among BRICS countries. But nevertheless e-commerce in India is growing thanks to increased number of Internet users, cheaper smartphones.

Share of cross-border e-commerce in 2018 in India was 74\% - the largest among BRICS countries. In 2018, Indians spent in cross-border e-commerce on the USA marketplaces US\$ 40.4 billion, UAE - US\$ 30.3 billion, Hong Kong - US\$ 12.2 billion, China - US\$ 9.9 billion, UK - US\$ 8.9 billion [10].

The advantages of e-commerce in India are: increase in a trade volume and growth rate (domestic and foreign); increase in the number of cross-border payments; small and medium-sized enterprises entry into the new markets; increased level and efficiency of cooperation between countries; new jobs creation.

The weakest aspects of e-commerce in India are as follows: insufficient Internet penetration, insignificant share of e-shoppers, small share of e-commerce in GDP, prefered payment method in e-commerce - cash on delivery.

China has announced the transition to a digital economy, part of which is the ecommerce. In recent years China has remained the largest e-commerce market throughout the world. China has surpassed United States as the leading market for both B2B and B2C e-commerce. In 2017, the volume of B2C e-commerce in China reached US\$ 682 billion, which is significantly more than in the United States (the second in the list) and the UKUS\$ 196 billion (the third). China occupies $37 \%$ of the global e-market. E-commerce turnover per capita in China is only about US\$ 5, but e-commerce turnover per Internet user is about US\$ 900. This is due to a slight Internet penetration into the country. China is the leader in the number of Internet users in the world, but the Internet penetration there is still lagging behind developed countries. In China that figure was $55.7 \%$, slightly above the regional average [10].

Volume of e-commerce is dependent on how often and how much consumers are willing to purchase. Average spending per online buyer is growing every year. In 2014, the figure was US\$ 1,228, and in 2017 - US\$ 1,425 [9].

In China, contribution of e-commerce to GDP was $4.5 \%$ (the biggest in the world). Internet penetration was 55,7\% Internet users of the total population in China, in 2017. Share of e-shoppers was $73.7 \%$ [10]. Share of Chinese e-commerce of total retail turnover was $28,6 \%$ in 2018 .

Internet giants Alibaba and JD.com continue to dominate the local market, together accounting for more than $85 \%$ of Chinese e-commerce market. The $3^{\text {rd }}$ e-commerce platform of China is Pinduoduo. There 300,000 products and more than 100 million users on this platform.

Chinese business has already started experiments with the delivery of goods with the help of robots and drones. In 2018, share of cross-border e-commerce in China was 58 [10]. Chinese spent in cross-border e-commerce on the marketplaces of Hong Kong US\$ 285 billion, of South Korea - US\$ 124 billion, of the USA - US\$ 115 billion, of Japan - USA\$ 113 billion, of Germany - US\$ 85 billion. Since 2005, a number of legislations, key rules, and guiding opinions have been promulgated to promote e-commerce development, reinforce laws and regulations, and construct and standardize the e-commerce market [16].

The introduction of e-commerce in rural areas is playing an important role in tackling China's poverty alleviation problem. Expanding opportunities for participation in rural e- 
commerce of farmers, poor households will contribute to the development of human capital [16].

South Africa is one of the largest B2C e-commerce markets in Africa and among regional leaders in the Internet, as well as in the field of mobile telephony. At the same time, only $65 \%$ of the population of South Africa has access to the Internet and only a 57\% of Internet users made online purchases in 2018 [10]. The South African marketplace B2B business model is a fast-growing market with 149,200 registered members offering 34.1 thousand products [17].

In South Africa, e-commerce share in GDP was only $0.91 \%$. An increase of the ecommerce share in GDP can become an economic growth driver. Average spending per eshopper in South Africa increased from US\$ 78 in 2015 to US\$ 157 in 2018. Share of cross-border e-commerce in 2018 in South Africa was 50\%. In 2018, customers of South Africa spent in cross-border e-commerce on the marketplaces of China US\$ 15.5 billion, of Germany - US\$ 7.03 billion, of the USA - US\$ 5.47 billion [10].

\section{Conclusions}

On the base of provided analysis, authors identify the advantages and barriers of ecommerce the BRICS countries, make recommendations on the development of an effective e-commerce platform of «five» states. The main benefits of e-commerce are: a) increase in GDP; b) the growth of domestic and international trade; c) improving the structure of international trade; d) reducing the cost of organizing trade; e) the ability to enter new markets for products; f) development and improvement of the efficiency of trade and investment cooperation; g) expansion of trade and distribution value chains; $h$ ) development of small business; i) creation of new jobs; j) social development of the country's population, including in remote and depressed areas; $\mathrm{k}$ ) introduction of new forms for goods and services using the Internet.

The main barriers of the implementation of international e-commerce between the BRICS countries are: a) insufficient information about the possibilities of e-commerce for business development; b) absence of an electronic payment system between foreign legal entities; c) weak e-commerce promotion; d) insufficient Internet penetration into the sphere of small and medium business in some of BRICS countries (for example, in Brazil and India); e) difficulties in finding a reliable partner; f) weak trust in both suppliers and buyers in e-commerce; g) linguistic and cultural differences; h) delivery speed - sometimes is not satisfied in some of the BRICS countries; i) main payment method in all the BRICS countries is cash payment on delivery (in India $-57 \%$, in Brazil $-50 \%$, in China $-33 \%$, in Russia - 24\%, in South Africa - $8 \%$ ).

To form an effective e-commerce platform for the BRICS countries, authors gave recommendations for strengthening e-commerce cooperation within BRICS countries: a) standardization of legal, administrative and technical regulation in the field of electronic commerce; b) development of a roadmap for the development of electronic commerce; c) creation of barrier-free regulation of electronic commerce; c) development of measures to ensure the protection of personal data in e-commerce; d) the use of blockchain technology in determining cross-border electronic transactions; e) to create and use the cryptocurrency of the BRICS countries in mutual e-commerce; f) creation of a unified database for the development of electronic commerce; g) to use such innovative technologies as the Internet of Things, Big Data for the development of e-commerce; h) assisting small businesses in the development of electronic commerce; i) creation of logistics hubs (electronic ports) to facilitate and accelerate customs clearance of goods; $j$ ) implementation of technology exchange in the organization of e-commerce; $k$ ) conducting joint research in the field of ecommerce development. 
Expansion of e-commerce will stimulate the growth of trade between the BRICS countries, which will affect the development of their economies.

\section{Acknowledgements}

This study was financed by a grant from the Plekhanov Russian University of Economics, Moscow, Russia \# 969 05.08.2020,\#1232 08.10.2020

\section{References}

1. A. Nogoev, R. Yazdanifard, S. Mohseni, B. Samadi, M. Menon (2011), https://www.researchgate.net/

2. World Trade Organization (1998), https://www.wto.org/

3. OECD (1997), https://www.oecd.org/

4. OECD (1997), https://www.oecd-ilibrary.org/

5. BRICS E-commerce Cooperation Initiative (2017), https://www.brics2017.org/

6. Jialong Xie, Lijun Wang, Microprocessors and Microsystems, 80, 103595 (2020)

7. Bruno Moriset, International Encyclopedia of Human Geography (Second Edition), 1 (2020)

8. UNESCO (2018), http://uis.unesco.org/

9. Global Ecommerce Report (2017), https://mazarsusa.com/

10. Ecommerce Foundation (2018), https://www.internetalliance.my/

11. Global Rus Trade (2020), https://www.globalrustrade.com/

12. B2W Digital (2016), http://hotsites.b2wdigital.com/

13. Association of Internet Commerce Companies (2020), http://www.akit.ru/

14. Dazeinfo (2018), https://dazeinfo.com/

15. eMarketer (2018), https://www.emarketer.com/

16. Haiying Lin, Ruihua Li, Wenlong Li, Alexandria Engineering Journal (2020)

17. New South Africa B2B Portal (2020), https://www.foreign-trade.com/ 